\title{
Predictors of consistent condom use based on the Information-Motivation-Behavioral Skills (IMB) model among female sex workers in Jinan, China
}

\author{
Hua Zhang ${ }^{1}$, Meizhen Liao ${ }^{2}$, Xijuan Nie ${ }^{3}$, Rongjian Pan ${ }^{3}$, Chuangxin Wang ${ }^{3}$, Shiman Ruan ${ }^{4}$, Changqing Zhang ${ }^{4}$,
} Xiaorun $\mathrm{TaO}^{2}$, Dianmin Kang ${ }^{2^{*}}$, Baofa Jiang ${ }^{1 *}$

\begin{abstract}
Background: Female commercial sex workers (FSWs) are at high risk of human immunodeficiency virus (HIV) transmission in China. This study was designed to examine the predictors of condom use with clients during vaginal intercourse among FSWs based on the Information-Motivation-Behavioral Skills (IMB) model and to describe the relationships between IMB model constructs.

Methods: A cross-sectional study was conducted in Jinan of Shandong Province, from May to October, 2009. Participants ( $N=432$ ) were recruited using Respondent-Driven Sampling (RDS). A self-administered questionnaire was used to collect data. Structural equation modeling was used to assess the IMB model.

Results: A total of 427 (98.8\%) participants completed their questionnaires. Condom use was significantly predicted by social referents support, experiences with and attitudes toward condoms, self-efficacy, and health behaviors and condom use skills. Significant indirect predictors of condom use mediated through behavioral skills included HIV knowledge, social referents support, and substance use.

Conclusions: These results suggest that the IMB model could be used to predict condom use among Chinese FSWs. Further research is warranted to develop preventive interventions on the basis of the IMB model to promote condom use among FSWs in China.
\end{abstract}

\section{Background}

Since the $1980 \mathrm{~s}$ the number of female commercial sex workers (FSWs) has markedly increased in China [1]. The number of women engaging in commercial sex is estimated to be 4 to 10 million [1,2]. Commercial sex plays a critical role in heterosexual transmission of human immunodeficiency virus (HIV) in China [1]. Approximately 127,000 female sex workers and their clients were living with HIV/AIDS, accounting for 19.6\% of the total number of estimated HIV cases at the end of 2005 [3]. Heterosexual sexual transmission among cumulative HIV infection increased from $10.7 \%$ in 2005 to $37.9 \%$ in 2007 , accounting for $44.7 \%$ of the 50,000

\footnotetext{
*Correspondence: dianminkang@sina.cn; jiangbaofa@sina.cn 1 Department of Epidemiology and Biostatistics, School of Public Health, Shandong University, Jinan, Shandong Province 250012, China ${ }^{2}$ Institute for AIDS/STD Control and Prevention, Shandong Province CDC, Jinan, Shandong Province 250014, China

Full list of author information is available at the end of the article
}

estimated new infections in 2007 [4]. Heterosexual transmission of HIV through contact with FSWs is of particular concern $[2,4,5]$. Data from national sentinel surveillance indicated that the prevalence of HIV among FSWs averaged $1 \%$, with the highest rates at $10 \%$ in several sites [6].

Sex trade is not accepted by Chinese ethical standards and there is a substantial stigma to FSWs. They are discriminated and marginalized in China [7]. In addition, the sex trade in China is clandestine due to unfavorable laws that impose fines and incarceration on FSWs and their clients if arrested. However, some women become FSWs possibly due to being attracted by the relatively high income. According to previous reviews, most FSWs in China are young, mobile, less educated, and some FSWs have also reported substance abuse $[1,5]$. They often trade sex in entertainment establishments/service sectors (e.g. dance hall, night clubs, restaurants, barber

\section{C) Biomed Central}


shop, and sauna parlors), are less likely to use condoms, and have high rates of sexually transmitted infections (STIs) $[1,5]$.

Given lack of effective vaccine or treatment of HIV, changing an individual's risk behaviors is crucial to prevent the spread of HIV. Consistent and correct condom use seems to be the most effective form of HIV prevention among FSWs. However, a recent review reported rates of consistent condom use with clients among FSWs in China of between $13 \%$ and 54\% [1]. Recent national comprehensive surveillance data showed that $60 \%$ of FSWs in China do not use condoms regularly [4]. It would be imperative to determine predictors of consistent condom use among FSWs to develop effective interventions for the prevention of HIV spread in China.

The Information-Motivation-Behavioral Skills (IMB) model developed by Fisher and his colleagues was designed to predict HIV preventive behavior and necessary elements HIV prevention intervention [8,9]. The conceptualization of the IMB model holds that HIV prevention information, motivation, and behavioral skills are the fundamental determinants of HIV preventive behavior. The model assumes that HIV prevention information and motivation affect risk-reduction behavioral change largely through behavioral skills. Information and motivation may also have direct effects on HIV preventive behavior, particularly when the behavior requires relatively uncomplicated behavioral performances. Furthermore, HIV prevention information and motivation are regarded as independent constructs, demonstrated by well-informed people who are not motivated to practice preventive behaviors, and by individuals who are motivated to practice preventive behaviors but are not well informed $[9,10]$.

The IMB model has been successfully tested in a variety of risk groups [11-20]. The constructs of the IMB model are regarded as highly generalizable determinants of HIV preventive behaviors in any population [9]. The current study used the IMB model as the theoretical framework to determine predictors of condom use among FSWs. According to the IMB model, motivation to engage in HIV preventive behaviors includes three factors that affect motivation to act: attitudes, social norms, and perceptions of personal vulnerability. Social norms are hypothesized to be a function of a person's perceptions of what social referents think should be done regarding the behavior multiplied by the person's motivation to comply with social referents $[9,21]$. The motivation to comply represents the extent to which a person wants to act as a reference group member and is assessed by the importance of social referents' belief [21]. Social norms, the perceptions of social referents support, and motivation to comply can affect HIV prevention intentions and behaviors [9]. In the literature, social referents support for condom use was used as one of indicators of motivation $[10,15-17,20]$. Pro-condom norms, which were assessed by the importance of the approval of referents in using condoms, significantly predicted condom use and self-efficacy in adolescent substance use study [18]. To examine the role of the motivation to comply within the context of the IMB model among FSWs, it has been hypothesized that the motivation to comply and the perceptions of social referents support were two indicators of social norms. Fisher holds that specific social referents support is salient for HIV preventive behaviors within a given population, and that perceptions of social norms for HIV prevention behaviors should be adjusted to increase motivation to perform such behaviors [9]. In the current study, peers, employers, and clients were regarded as social referents because their support has been demonstrated to be significantly associated with consistent condom use among FSWs [22-28].

Fisher has identified a broad range of behavioral skills that are assumed to be necessary for HIV preventive behaviors [29]. "Universal" HIV prevention behavioral skills include the objective ability to perform such acts and a sense of self-efficacy for doing them, such as skills to negotiate HIV preventive behavior, to engage in public behaviors such as HIV testing and condom purchasing, and to avoid drinking or drug use before sex $[9,16,30]$. Bandura holds that one must possess these behaviors and self-efficacy to engage in HIV prevention [31]. Measures of self-efficacy for performing a behavior have been commonly used in previous studies $[10,16,17,20]$. Self-efficacy may not completely represent skill performance as much as personal acceptance for practicing a skill and engaging in the public behaviors. Two indicators of behavioral skills have been assessed: condom self-efficacy and condom use skills among adolescent population and mentally ill adults $[18,19]$. The two studies demonstrated that condom application skills were significantly associated with certain factors (e.g., condom attitudes), but were not related to condom use. In the current study, measures of both self-efficacy and health behaviors and condom use skills were used as indicators of behavioral skills.

In addition, many studies have reported that substance use is the greatest risk factor for HIV/STI infection and for inconsistent condom use among FSWs [6,32-35]. In China, sentinel sites with FSWs who use drugs had higher HIV rates than those sites with only non-drugusing FSWs [36]. Fisher also holds that "universal" HIV prevention behavioral skills may be relevant to substance use [9]. Therefore, substance use status was added to this model.

The current study aimed to explore predictors of condom use during vaginal intercourse between FSWs and 
clients within the context of the IMB model and to examine the relationships between these constructs of the model. It was hypothesized that information, motivation, and substance use would predict both health behaviors and condom use skills and self-efficacy, and these indices of behavioral skills would, in turn, predict condom use.

\section{Methods}

\section{Study site}

The study was conducted from May to October 2009 in Jinan, the capital city of Shandong Province, with about 3 million of permanent residents and 1.5 million of migrants. The majority $(98.2 \%)$ of the population in Jinan are Han Chinese.

A total of 2,167 HIV/acquired immunodeficiency syndrome (AIDS) cases have been reported in Shandong by the end of 2008; heterosexual transmission was the major transmission route [37]. In Jinan, it is estimated that 50,000-100,000 employees work in entertainment establishments and about one-third of them are sex workers [38]. Recent surveillance results showed that $30.2 \%$ of HIV-positive cases in Jinan were infected through heterosexual transmission [39].

\section{Recruitment of seeds and study participants}

Respondent-Driven Sampling (RDS) was used to recruit participants. RDS is an adaptation of chain-referral sampling and a suitable sampling method for hidden populations, which can provide relatively unbiased and representative population-based estimates [40,41].

The selection criteria for eligible FSW seeds and participants were defined as "a female over the age of 18 who has exchanged sex for money and has lived in Jinan in the past month and is not inebriated at the interview." Each seed or participant was asked to recruit no more than three peers.

Six seeds were initially selected and told how to refer other eligible FSWs. Each seed was given three uniquely coded coupons to refer their peers. Coupons were given to participants until approximately 350 participants were recruited, to obtain a target sample size of approximately 400 FSWs. Seeds and their recruits were given an incentive package including 50 Yuan $(\mathbb{5 0}$, equal to U.S. \$ 7.32), HIV prevention pamphlets and four boxes of condoms for successfully participating, plus an additional 20 (U.S. \$ 2.93) for recruiting a FSW. A total of 957 coupons were given out to 319 FSWs, and 9 females refused to participate in the study.

A structured questionnaire was used to collect data administered by trained female interviewers. An informed consent form was read to each candidate, describing the potential risks and benefits of the research. Interviewers explained to every candidate that voluntary participation, anonymity, and confidentiality were ensured. The participants privately completed a self-administered questionnaire. For participants with limited literacy (about 2.1\%), only one interviewer who provided assistance as needed was allowed to stay with the participant, and the interviewer read each question and response options from the questionnaire, while the participant marked the response on her own questionnaire. A total of 432 FSWs were recruited. The numbers of missing data for all variables ranged from 3 to 1 . Cases with any missing data were excluded, resulting in a sample size of 427 . The study protocol was approved by the Ethics Review Committee of Shandong University.

\section{Measures}

A structured questionnaire was developed to collect data on demographics, such as age, ethnicity, education, permanent residence, marital status, and the constructs of the IMB model. The IMB model constructs included HIV/AIDS prevention information, motivation, behavioral skills, and prevention behaviors. Each measure of the IMB model constructs is described below.

\section{Information}

Information was measured with 18 items scaled 0-1 that assessed FSW knowledge about HIV/AIDS [42-44]. One indicator containing 11 items was related to HIV transmission (e.g., Do you think people can catch AIDS by blood transfusion?); another one containing 7 items was related to HIV prevention (e.g., Do you think correctly using a condom during every sexual intercourse can prevent HIV infection?). Participants were asked whether the statements were true or false, or unknown. "Don't know" responses were coded as incorrect answers. Cronbach's alpha coefficient for the $11 \mathrm{HIV}$ transmission related items and 7 HIV prevention related items was 0.78 , and 0.81 , respectively.

\section{Motivation}

Experiences with and attitudes toward condoms were assessed with 7 true or false questions. Typical items included: "Condom use causes too much trouble" and "Condom use is safer than other methods." The number of answers indicating a positive attitude served as an indicator of experiences with and attitudes toward condoms. The composite score ranged form 0 to 7 . Cronbach's alpha coefficient for the 7 items was 0.80 .

Social referents support contained three indicators, assessed with nine items from Bazargan [15], Yang [22], Kerrigan [23], and Wang [26]. In the current study, peers, employers, and clients were regarded as social referents. Typical items included "how much would your employer approve or disapprove of your use of condoms with clients?" and "how much would your employer approve or disapprove of you talking about 
safe sex with clients?" Each item was scored 1 (disapprove strongly) to 5 (approve strongly). The means of the responses associated with the three items for each social referent were calculated yielding three items as indicators of social referents support. Cronbach's alpha coefficient ranged from 0.75 to 0.83 for three subscales of social referents support.

Motivation to comply was measured by three items indicating the importance of the approval of peers/ employers/clients in using condoms [21]. Responses ranged from 1 (extremely unimportant) to 5 (extremely important). Cronbach's alpha coefficient was 0.68 .

Perceived risk was indicated by three items that asked (a) the extent to which the FSW was about getting AIDS on a scale ranging from 1 (not at all worried) to 5 (extremely worried); (b) her risk of getting AIDS on a scale ranging from 1 (very low) to 5 (very high); and (c) her risk of getting a sexually transmitted infection on a scale from 1 (very low) to 5 (very high) [45]. Cronbach's alpha coefficient was 0.56 .

\section{Substance use}

Substance use was measured by two items. Item 1 asked if the FSW has used non-injection drugs. Item 2 asked how many times the FSW drunk alcohol in the last week. Non-injection drugs use was scored 0 and no drugs use was scored 1. No alcohol use was scored 5; the frequencies of alcohol use that ranged from 1 to 2,3 to 4,5 to 6 , and more than 7 were scored $4,3,2$, and 1 , respectively. Higher scores indicated lower frequencies of alcohol use in the last week. Another item, indicating whether the FSW had ever used injection drugs, was eliminated because answers revealed that only $0.7 \%$ of FSWs reported that they had ever used injection drugs. Cronbach's alpha coefficient for the two items was 0.61.

\section{Behavioral skills}

Health behaviors and condom use skills were assessed by four indicators [9,11]. For instance, "Have you been HIV tested in the last year?" and "Was condom always available?" Condom use skills were measured as a composite score, which is the sum of the 5 item scores. The 5 items were measured as dichotomous variables $(0=$ no, 1 = yes), asking whether woman had performed correct condom use: (a) checking the expiration date and opening the condom package without tearing the condom; (b) pinching the tip of the condom to remove air; (c) putting the condom on the client before intercourse; (d) the condom being rolled to the base of the erect penis; (e) after ejaculation, holding the rim of the condom and pulling the penis out before it got soft [22]. Cronbach's alpha coefficient was 0.76 for the 5 items.

Self-efficacy in practicing HIV prevention was assessed by 8 items $[11,22,46]$. Three items were used to measure self-efficacy for condom negotiation skills. Typical items included "Can you discuss safe sex with your clients before sex?", and "Can you persuade your clients to use a condom if he is unwilling to use it?". Cronbach's alpha coefficient for the 3 items was 0.83 . A composite score was created using the mean of three items that were scored 1 (very difficult) to 5 (very easy). Three items were used to measure self-efficacy about refusing unprotected sex (e.g., "Can you refuse to have sex with client when he does not use a condom by extra money?") Cronbach's alpha coefficient for the 3 items was 0.85 . Similarly, a composite score was created using the mean of three items that were scored 1 (very difficult) to 5 (very easy). Self-efficacy for acquiring HIV prevention information and self-efficacy for avoiding drinking or drug use before sex was respectively measured by one item that was scored from 1 (very difficult) to 5 (very easy).

\section{Percent condom use}

The percentage of condom use was used as the dependent variable in the study. It was calculated by the times of condom use divided by the number of vaginal intercourse during vaginal intercourse with clients in the last month.

\section{Data analysis}

Descriptive statistics, such as means, standard deviations, frequencies, and percentages were reported. The hypothetical IMB was examined by structural equation model (SEM) using the LISREL [47]. SEM compares a proposed hypothetical model elucidating relationship with a set of actual data. The closeness of the variancecovariance matrix implied by the hypothetical model to the empirical variance-covariance matrix is evaluated through goodness-of-fit indices, including maximum likelihood chi-square values/degrees of freedom ratio, the comparative fit index (CFI), the root mean square errors of approximation (RMSEA), and the non-normed fit index (NNFI). Good fit (a chi-square valueless than twice the degrees of freedom in the model; CFI $\geq 0.95$; $\mathrm{NNFI} \geq 0.95$; RMSEA < 0.06 ) was used to justify interpretation of parameters $[15,47,48]$.

Confirmatory factor analysis (CFA) was conducted to examine the factor structure (measurement model) and the relationships among all the latent variables and manifest variables. Once the factor structure was confirmed, a path model was performed to examine the predicting effects of all study variables on condom use and the effects of HIV preventative information and motivation on behavioral skills. In an effort to generate a parsimonious model, non-significant paths were gradually dropped until only significant paths remained. In the trimming of the model, we first reviewed the path coefficients. One non-significant path was eliminated, and the difference $x^{2}$ was evaluated at each step. Nonsignificant improvement in the $x^{2}$ value would indicate that it was acceptable to trim this path. 


\section{Results}

Table 1 presents sample demographics. Mean age of the sample was 29.6 years $(\mathrm{SD}=7.4), 66.7 \%$ were older than 25 years, $27.4 \%$ had first lifetime sex at $<18$ years of age, 99.1\% was Han in ethnicity, $66.0 \%$ received middle school education or less, and $32.6 \%$ were divorced or widowed. Most of the participants (81.5\%) reported having noncommercial steady sexual partner(s) and $45.7 \%$ had no children. The mean number of clients was $4.5(\mathrm{SD}=3.4)$ in the last week and the mean number of clients in the last month was 14.3 ( $\mathrm{SD}=8.2)$. The mean number of FSWs which the participants knew in Jinan was 12.5 (SD $=7.9)$. The majority $(82.7 \%)$ earned more than 2,000 Yuan (or approximately U.S. \$ 300) per month, 13.6\% satisfied the client's desire for sex without using a condom if extra money was provided, and $63.9 \%$ reported ever had STD-related symptoms in the past year.

The mean of the percent of correct responses to HIV prevention knowledge was only $45.7 \%$ and the mean of

Table 1 Sociodemographic characteristics of female sex workers ( $N=427)$

\begin{tabular}{|c|c|c|}
\hline Characteristics & Frequency & Percentage (\%) \\
\hline \multicolumn{3}{|l|}{ Age (years) } \\
\hline $18-20$ & 40 & 9.4 \\
\hline $21-25$ & 102 & 23.9 \\
\hline $26-53$ & 285 & 66.7 \\
\hline \multicolumn{3}{|l|}{ Ethnicity } \\
\hline Han & 423 & 99.1 \\
\hline Other & 4 & 0.9 \\
\hline \multicolumn{3}{|l|}{ Education level } \\
\hline Primary school or lower & 56 & 13.1 \\
\hline Middle school & 226 & 52.9 \\
\hline High school or higher & 145 & 34.0 \\
\hline \multicolumn{3}{|l|}{ Registered permanent residence } \\
\hline Jinan city & 56 & 13.1 \\
\hline Other city in Shandong & 145 & 34.0 \\
\hline Outside Shandong & 226 & 52.9 \\
\hline \multicolumn{3}{|l|}{ Martial status } \\
\hline Single & 103 & 24.1 \\
\hline Cohabitation & 68 & 15.9 \\
\hline Married & 117 & 27.4 \\
\hline Divorced or widowed & 139 & 32.6 \\
\hline \multicolumn{3}{|l|}{ Number of children } \\
\hline 0 & 195 & 45.7 \\
\hline 1 & 207 & 48.5 \\
\hline$\geq 2$ & 25 & 5.8 \\
\hline \multicolumn{3}{|l|}{ Monthly in come (Yuan ¥) } \\
\hline$\leq 2000$ & 74 & 17.3 \\
\hline$>2000$ & 353 & 82.7 \\
\hline \multicolumn{3}{|l|}{ Age at sex debut (years) } \\
\hline$\geq 18$ & 310 & 72.6 \\
\hline$<18$ & 117 & 27.4 \\
\hline
\end{tabular}

the percent of correct responses to HIV transmission knowledge was $61.2 \% .47 .1 \%$ of the women reported using condoms with clients every time during vaginal intercourse in the last month. In addition, $27.0 \%$ of the sample's clients supported condom use with FSWs during sexual intercourse. Only $19.4 \%$ of the women were tested for HIV in the past year.

\section{Confirmatory factor analysis}

The means, standard deviations, ranges, and factor loadings for constructs of the model are shown in Table 2. As shown in table 2, all factor loadings were significant $(p \leq 0.05)$. The fit statistics for the saturated model were acceptable: $x^{2}=386.61,197 d f$, CFI $=0.95$, RMSEA $=$ 0.05 , NNFI $=0.90$. The full model included all paths appears in Figure 1. Measured variables representing

Table 2 Summary statistics and factor loadings in confirmatory factor analyses

\begin{tabular}{|c|c|c|c|}
\hline & M & SD & $\mathrm{FL}^{*}$ \\
\hline \multicolumn{4}{|l|}{ Knowledge } \\
\hline Prevention knowledge (\% correct) & 45.7 & 25.7 & 0.69 \\
\hline Transmission knowledge (\% correct) & 61.2 & 21.4 & 0.66 \\
\hline \multicolumn{4}{|l|}{ Prevention Motivation } \\
\hline \multicolumn{4}{|l|}{ Perceived risk (1-5) } \\
\hline Fear about getting HIV & 4.3 & 1.1 & 0.45 \\
\hline Chance of getting HIV & 2.1 & 1.3 & 0.46 \\
\hline Chance of getting STDs & 3.3 & 1.1 & 0.41 \\
\hline \multicolumn{4}{|l|}{ Motivation to comply (1-5) } \\
\hline Motivation to comply with partner & 3.9 & 1.4 & 0.62 \\
\hline Motivation to comply with employer & 3.3 & 1.5 & 0.93 \\
\hline Motivation to comply with client & 3.2 & 1.6 & 0.62 \\
\hline \multicolumn{4}{|l|}{ Social referents support (1-5) } \\
\hline Partner support & 4.3 & 0.7 & 0.67 \\
\hline Employer support & 3.5 & 0.8 & 0.80 \\
\hline Client support & 3.3 & 0.9 & 0.65 \\
\hline Experiences with and attitudes toward condoms (0-7) & 4.3 & 2.0 & - \\
\hline \multicolumn{4}{|l|}{ Substance use } \\
\hline Alcohol use (1-5) & 2.7 & 1.5 & 0.52 \\
\hline Non-injection drugs use (0-1) & 0.9 & 0.3 & 0.47 \\
\hline \multicolumn{4}{|l|}{ Health behaviors and condom use skills } \\
\hline Condom accessibility (1-5) & 4.6 & 0.7 & 0.54 \\
\hline Condom use skills (1-5) & 3.5 & 1.5 & 0.60 \\
\hline HIV testing (0-1) & 0.2 & 0.4 & 0.59 \\
\hline Gynecological examination (0-1) & 0.6 & 0.5 & 0.52 \\
\hline \multicolumn{4}{|l|}{ Self-efficacy (1-5) } \\
\hline Condom negotiation skills & 3.1 & 0.6 & 0.63 \\
\hline Acquire HIV prevention information & 3.4 & 1.1 & 0.48 \\
\hline Refusal of unprotected sex & 3.1 & 0.9 & 0.85 \\
\hline Avoid drinking or drug use before sex & 3.7 & 1.3 & 0.44 \\
\hline Percent condom use & 0.9 & 0.2 & - \\
\hline
\end{tabular}




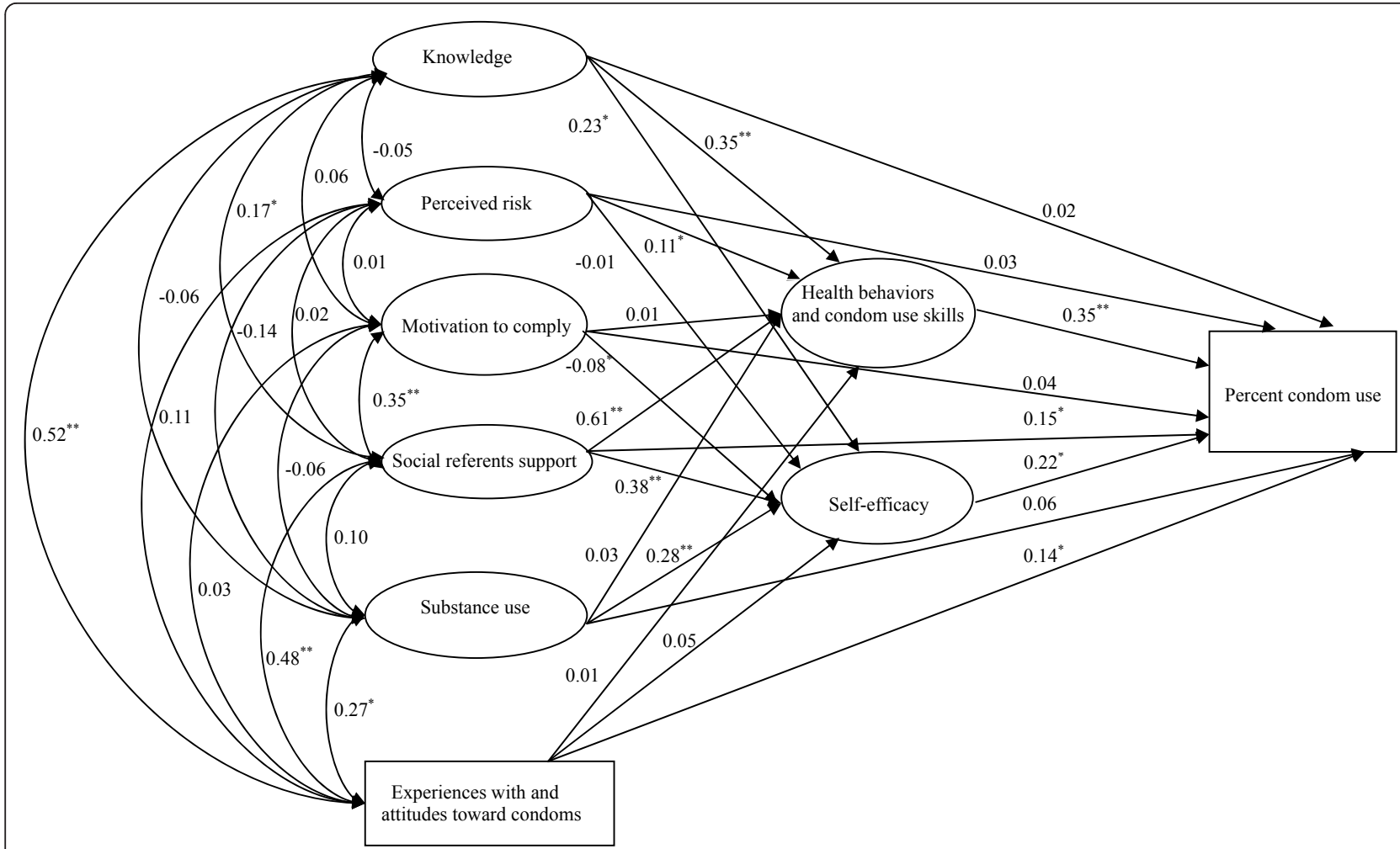

Figure 1 The full predictive IMB model. Structural equation model depicting regression paths in the IMB model ( $N=427)$. Large circles represent latent variables; rectangles represent single-item indicators. Single-headed arrows represent regression coefficients; double-headed arrows represent correlations. Regression coefficients are standardized ( $\left.{ }^{*} p \leq 0.05,{ }^{* *} p \leq 0.001\right)$.

latent constructs are in rectangles and the multiple indicator latent variables are in ovals. The full model predicted $42 \%$ of the variance for condom use, $62 \%$ of the variance for health behaviors and condom use skills, and $45 \%$ of the variance for self-efficacy.

Table 3 reports the bivariate correlations among constructs in the model without any directionality of influence among them. The correlations show that condom use was associated with social referents support, experiences with and attitudes toward condoms, substance use, health behaviors and condom use skills, and selfefficacy.

\section{Path models}

The final IMB model is depicted in Figure 2. The fit indices for the trimmed model were acceptable: $x^{2}$ $=405.50,206 d f$, CFI $=0.97$, RMSEA $=0.05$, NNFI $=$ 0.95. The explained variances for condom use, health behaviors and condom use skills, and self-efficacy were $38 \%, 57 \%$, and $43 \%$, respectively.

As shown in Figure 2, significant predictors of condom use were social referents support, experiences with and attitudes toward condoms, self-efficacy, and health behaviors and condom use skills. Health behaviors and condom use skills was significantly predicted by HIV

Table 3 Correlation among model variables

\begin{tabular}{|c|c|c|c|c|c|c|c|c|c|c|}
\hline & & $\mathrm{I}$ & II & III & IV & $\mathrm{v}$ & VI & VII & VIII & IX \\
\hline 1 & Knowledge & 1.00 & & & & & & & & \\
\hline$\|$ & Perceived risk & -0.05 & 1.00 & & & & & & & \\
\hline III & Motivation to comply & 0.06 & 0.01 & 1.00 & & & & & & \\
\hline IV & Social referents support & $0.17^{*}$ & 0.02 & $0.35^{++}$ & 1.00 & & & & & \\
\hline V & Experiences with and attitudes toward condoms & $0.52^{++}$ & 0.11 & 0.03 & $0.48^{++}$ & 1.00 & & & & \\
\hline $\mathrm{Vl}$ & Substance use & -0.06 & -0.14 & -0.06 & 0.10 & $0.27^{+}$ & 1.00 & & & \\
\hline VII & Health behaviors and condom use skills & $0.43^{++}$ & $0.15^{*}$ & 0.09 & $0.49^{++}$ & $0.47^{++}$ & $0.41^{++}$ & 1.00 & & \\
\hline VIII & Self-efficacy & $0.27^{+}$ & 0.08 & $-0.20^{+}$ & $0.41^{++}$ & $0.41^{++}$ & $0.29^{+}$ & $0.57^{++}$ & 1.00 & \\
\hline IX & Percent condom use & 0.03 & 0.02 & 0.09 & $0.37^{++}$ & $0.33^{++}$ & $0.24^{+}$ & $0.51^{++}$ & $0.55^{++}$ & 1.00 \\
\hline
\end{tabular}

${ }^{*} p<0.05 ;{ }^{+} p<0.01 ;{ }^{++} p<0.001$. 


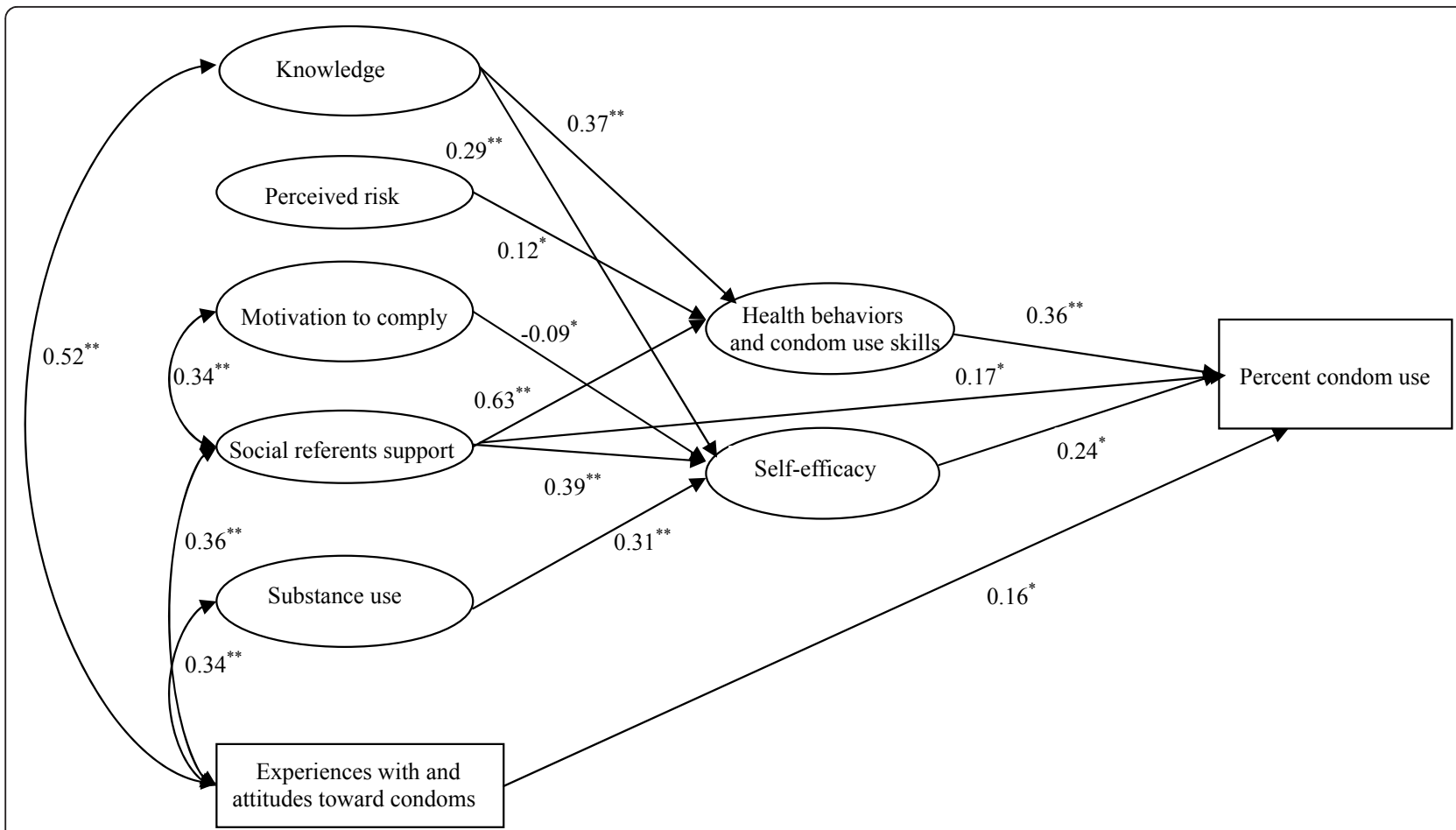

Figure 2 The final predictive IMB model structural equation model. Structural equation model depicting significant regression paths in the IMB model $(N=427)$. Large circles represent latent variables; rectangles represent single-item indicators. Single-headed arrows represent regression coefficients; double-headed arrows represent correlations. Regression coefficients are standardized $\left({ }^{*} p \leq 0.05,{ }^{* *} p \leq 0.001\right)$.

knowledge, perceived risk, and social referents support. Significant predictors of self-efficacy included HIV knowledge, motivation to comply, social referents support, and substance use.

The indirect effects on condom use as reported in the trimmed model were also examined. Variables that indirectly affected condom use through health behaviors and condom use skills or self-efficacy variables included HIV knowledge $(p \leq 0.001)$, social referents support $(p \leq 0.001)$, and substance use $(p \leq 0.05)$.

\section{Discussion}

The results of this research demonstrate the applicability of the IMB model in predicting HIV/STI risk behaviors among Chinese FSWs. The results of this study show that FSWs who possessed higher levels of social referents support, health behaviors and condom use skills, self-efficacy, and positive experiences with and attitudes toward condoms were more likely to use condoms with clients during vaginal intercourse.

In the current study, the direct effect of HIV knowledge on condom use was not significant. These results are consistent with prior research that used the IMB model with gay men and heterosexual college students [11], women of low-income housing [14], juvenile offenders [20], and substance use adolescents [18]. Bandura and Fisher hold that information is a necessary but often insufficient condition for the adoption of preventive behaviors $[11,49]$. Our findings confirm this among FSWs. However, our findings also demonstrate that the indirect effects of information were significant, mediated through health behaviors and condom use skills and self-efficacy to influence condom use. Furthermore, HIV knowledge was positively associated with experiences with and attitudes toward condoms. In addition, our data show that the level of knowledge of FSWs was lower than expected, especially the level of HIV prevention knowledge. Many misconceptions about sexual transmission remained among FSWs. For example, in our sample, about half of FSWs believed that showering or washing one's genitals/private parts after sex could prevent person from becoming infected with HIV; some FSWs believed that oral sex was safe if the discharge was not swallowed. These misconceptions may result in less compliance in using a condom. Many FSWs provided correct answers about HIV knowledge concerning nonsexual activities. For example, more than $80 \%$ of the FSWs answered the item "HIV infection spreads easily when people share needles for drug use with someone" correctly. These results suggest that more attention is needed toward strengthening education about specific HIV knowledge where it is lacking. 
Data in the current study confirm the role of social referents support and motivation to comply. Social referents support was positively associated with motivation to comply and experiences with and attitudes toward condoms. This finding implies that greater social referents support accompanies the strengthening of a person's motivation to comply and more positive experiences with and attitudes toward condoms. Furthermore, the direct and indirect effects of social referents support play an important role in condom use among women. Other studies among FSWs in China also found that perceived social referents support was significant with consistent condom use $[22,28,50]$. We did not find evidence for an association between motivation to comply and condom use while motivation to comply significantly predicted self-efficacy. When clients want or demand sex without a condom, the role of motivation to comply in FSWs' condom use decision-making may be undermined by power imbalances between FSWs and clients, fear of losing clients, and fear of being punished by employers for refusing the client's desire for sex without a condom. The results suggest that enhancing social referents support for condom use may be an important strategy to increase condom use. In addition, HIV intervention for FSWs needs to be multilevel, integrating social factors into the intervention. Encouraging a discussion about safe sex with their peers, and launching peer education among FSWs may lead to increasing levels of motivation. HIV interventions for FSWs should also include their employers. The key HIV interventions for employers include increasing their responsibility for safe sex and encouraging them to promote condom use. For instance, employers were trained to provide positive reinforcement of their employee' health sexual practices, and required to increase the availability of condoms and to promote FSWs' AIDS awareness [45,51]. Furthermore, HIV interventions should also include clients as a target population. Interventions for clients should focus on improving knowledge of HIV transmission and prevention, promoting pro-condom attitudes and behaviors, and increasing clients' access to condoms. Utilizing mass media to increase HIV knowledge, providing education concerning condom promotion for clients by sexual health services, and promoting social marketing strategy to increase clients' access to quality condoms may be effective approaches.

Perceived risk was positively associated with health behaviors and condom use skills. This result shows that the FSWs with a greater perception of risk were more likely to engage in health behaviors such as obtaining an HIV test and undergoing gynecological examinations. Perceived risk was not found to be significantly associated with the other factors. In this study, most FSWs perceived that their risk of getting infected with HIV was very low, while most FSWs had a high level of fear about getting infected with HIV. In addition, the perceived risk has a relatively low reliability estimate. These aspects may impact the associations between perceived risk and other factors. About one-third of FSWs were divorced/widowed, and so were the sole supporters of their families. Insistence on condom use could result in the loss of clients, meaning that FSWs may meet clients' demand for sex without a condom when the clients provide extra money. At the same time, lack of awareness of their high-risk status also may lead to unprotected sex. FSW' needs for income may be more important than concerns about personal health, until clients become more accepting of condom use [52]. Therefore, HIV/AIDS interventions should increase the awareness of FSWs about HIV and should address assertiveness training to refuse unsafe sex.

When behavioral skills were divided into health behaviors and condom use skills and self-efficacy, the effects of two indicators of behavioral skills were significant while the effects of health behaviors and condom use skills were slightly stronger than the effects of self-efficacy. Self-efficacy was significantly associated with condom use, which was consistent with prior research among FSWs in China [26]. Furthermore, health behaviors and condom use skills mediated the potential effects of knowledge, perceived risk, and social referents support on condom use. These findings indicate that health behaviors and condom use skills play an important role in condom use in this sample. A few FSWs obtained an HIV test within the previous year, which is consistent with a recent study about FSWs in China [50]. Approximately 40\% of FSWs reported that they had never had a gynecological examination in the last year. Previous studies reported that FSWs in China associate physical appearance with their health status $[53,54]$. Frequent unprotected sex is more likely to result in reproductive tract infections and sexually transmitted diseases in FSWs. Therefore, an awareness of the importance of engaging in health-promoting behaviors should also be developed in FSWs.

This study revealed that an indirect effect of substance use on condom use was significant and that lower levels of substance use accompanied positive experiences with and attitudes toward condom. In addition, substance use significantly affected self-efficacy. Higher levels of substance use may enhance intentions to seek sexual sensation and engage in high-risk sexual behavior, and express more negative condom attitudes [34,35,55-57]. Substance use may impair FSWs' mental judgment, inhibition, and the ability to negotiate condom use [56-59]. It is also possible that financial need to purchase drugs would place FSWs in a less favorable negotiating position for condom use with their clients [59]. These may 
lead to that FSWs with higher levels of substance use have lower self-efficacy for condom use. The current study did not find a significant relationship between substance use and health behaviors and condom use skills. Substance use may not be relevant to health behaviors that may be influenced by HIV knowledge, perceived risk, discrimination, etc. $[38,60]$. This would decrease the salience of health behaviors and condom use skills associated with substance use. The results suggest that future interventions should strengthen FSW understanding about the hazards of drug abuse and alcohol intoxication and reduce substance use risk behaviors among FSWs.

However, there are potential limitations to our study that suggest some caution when drawing conclusions or making generalizations from our findings. A potential limitation to this study is the cross-sectional research design that limits the ability to establish causal associations.

RDS was applied in this study to collect data among FSWs. Most studies about FSWs in China have been based on institutionalized subjects or on women working in entertainment or personal service sectors, where it is extremely difficult to obtain random samples [1]. RDS has seldom been used to study FSWs in China [61]. The financial incentive that motivates participation may not be suitable or be too little for high-income FSWs. Therefore, FSWs who earned a high income were seldom recruited [62], which may affect the representative of the sample. Additionally, RDS yields a relatively unbiased sample. Hence, our sample is an approximate representative of FSWs in Jinan.

Another limitation of this study is the self-reported nature of the questionnaire. Despite a data collection protocol designed to minimize this potential limitation, we recognize that self-reporting bias may exist. The reliability of study participant responses may be questionable due the sensitive nature of responses about sexual practices, substance use, etc. Some constructs of the IMB model in this study have relatively low reliability estimates (e.g., 0.56 for perceived risk, 0.61 for substance use), from which it is likely that this would have served to underestimate associations between constructs of the IMB model.

\section{Conclusions}

The specific elements of the IMB model that are critical for condom use among FSWs were identified and confirmed the central proposition that information and motivation works mainly through behavioral skills to influence HIV prevention behaviors. The relationships between constructs of the IMB model were also examined. Our findings have implications for the development of HIV risk reduction interventions for FSWs.
Further study should explore effective interventions based on the current study's findings.

\section{Abbreviations}

FSWs: female commercial sex workers; IMB: Information-MotivationBehavioral Skills; RDS: respondent-driven sampling; HIV: human immunodeficiency virus; STI: sexual transmitted infection; AIDS: acquired immunodeficiency syndrome; SEM: structural equation modeling; CFI: the comparative fit index; RMSEA: the Root Mean Square Errors of Approximation; NNFI: the Non-Normed Fit Index; CFA: initial confirmatory factor analysis; SD: standard deviation; M: Mean; FL: factor loadings.

\section{Acknowledgements}

The authors would like to thank team members from Shandong Province CDC, Jinan City CDC, Licheng District CDC for their contributions to design of this research and collect the data.

\section{Author details}

${ }^{1}$ Department of Epidemiology and Biostatistics, School of Public Health, Shandong University, Jinan, Shandong Province 250012, China. ${ }^{2}$ Institute for AIDS/STD Control and Prevention, Shandong Province CDC, Jinan, Shandong Province 250014, China. ${ }^{3}$ Institute for AIDS/STD Control and Prevention, Licheng District CDC, Jinan, Shandong Province 250100, China. ${ }^{4}$ Institute for AIDS/STD Control and Prevention, Jinan City CDC, Jinan, Shandong Province 250000, China.

\section{Authors' contributions}

All authors contributed the design of this research. $\mathrm{HZ}$ conducted field study, collated the data, conducted statistical analyses, and prepared the first draft of the manuscript. BJ conceptualized the study, provided statistical support to the study and edited the manuscript. DK coordinated all research activities, edited the manuscript. ML provided statistical support to the study. $J N, R J, C W, S R, C Z$, and XT played a major role in the field survey. All authors read and approved the final manuscript.

\section{Competing interests}

The authors declare that they have no competing interests.

Received: 2 August 2010 Accepted: 17 February 2011 Published: 17 February 2011

\section{References}

1. Hong Y, Li XM: Behavioral studies of female sex workers in China: a literature review and recommendation for future research. AIDS Behav 2008, 12:623-636.

2. Tucker JD, Henderson GE, Wang TF, Huang YY, Parish W, Pan SM, Chen XS, Cohen MS: Surplus men, sex work, and the spread of HIV in China. AIDS 2005, 19:539-547.

3. China Ministry of Health, UNAIDS, WHO: 2005 Update on the HIV/STD epidemic and response in China. Beijing: China Ministry of Health; 2006.

4. State Council AIDS Working Committee Office UN Theme Group on AIDS in China: A joint assessment of HIV/AIDS prevention, treatment and care in China: 2007. Beijing: State Council AIDS Working Committee Office; 2007.

5. Yang $H$, Li X, Stanton B, Liu H, Liu H, Wang N, Fang XY, Lin DH, Chen XG: Heterosexual transmission of HIV in China: a systematic review of behavioral studies in the past two decades. Sex Transm Dis 2005, 32:270-280.

6. China CDC: National behavioral and biological surveillance report: 2007. Beijing: National Center for AIDS/STD Control and Prevention, China CDC; 2008.

7. Yan H, Li XM, Fang XY, Zhao R: Depressive symptoms and condom use with clients among female sex workers in China. Sex Health 2007, 4:99-104.

8. Fisher JD, Fisher WA, Misovich SJ, Kimble DL, Malloy TE: Changing AIDS risk behavior: effects of an intervention emphasizing AIDS risk reduction information, motivation, and behavioral skills in a college student population. Health Psychol 1996, 15:114-123.

9. Fisher JD, Fisher WA: Changing AIDS risk behavior. Psychological Bulletin 1992, 111:455-474 
10. Kalichman SC, Picciano JF, Roffman RA: Motivation to reduce HIV risk behaviors in the context of the information, motivation and behavioral skills (IMB) model of HIV prevention. J Health Psychology 2008, 13:680-689.

11. Fisher JD, Fisher WA, Williams SS, Malloy TE: Empirical tests of an information-motivation-behavioral skills model of AIDS-preventive behavior with gay men and heterosexual university students. Health Psychol 1994, 13:238-250.

12. Bryan AD, Fisher JD, Fisher WA, Murray DM: Understanding condom use among heroin addicts in methadone maintenance using the information-motivation-behavioral skills model. Subst Use Misus 2000, 35:451-471.

13. Bryan $A D$, Fisher JD, Benziger TJ: Determinants of HIV risk among Indian truck drivers. Social Science and Medicine 2001, 53:1413-1426.

14. Anderson ES, Wagstaff DA, Heckman TG, Winett RA, Roffman RA, Solomon LJ, Cargill V, Kelly JA, Sikkema KJ: Information-MotivationBehavioral Skills (IMB) model: testing direct and mediated treatment effects on condom use among women in low-income housing. Ann Behav Med 2006, 31:70-79.

15. Bazargan M, Kelly EM, Stein JA, Husaini BA, Bazargan SH: Correlates of HIV risk-taking behaviors among African-American college students: the effects of HIV knowledge, motivation, and behavioral skills. J Natl Med Assoc 2000, 92:391-404

16. Fisher JD, Fisher WA, Bryan AD: Information-motivation-behavioral skills model-based HIV risk behavior change intervention for inner-city high school youth. Health Psychol 2002, 21:177-186.

17. Harman JJ, Amico KR: The relationship-oriented information-motivationbehavioral skills model: a multilevel structural equation model among dyads. AIDS Behav 2009, 13:173-184

18. Kalichman S, Stein JA, Malow R, Averhart C, Dévieux J, Jennings T, Prado G, Feaster DJ: Predicting protected sexual behaviour using the information-motivation-behaviour skills model among adolescent substance abusers in court-ordered treatment. Psychol Health Med 2002, 7:327-338.

19. Kalichman S, Malow R, Dévieux J, Stein JA, Piedman F: HIV risk reduction for substance using seriously mentally ill adults: test of the informationmotivation-behavior skills (IMB) model. Community Ment Health J 2005 , 41:277-290.

20. Robertson AA, Stein JA, Baird-Thomas C: Gender differences in the prediction of condom use among incarcerated juvenile offenders: testing the information-motivation-behavior skills (IMB) model. Journal of Adolescent Health 2006, 38:18-25.

21. Stiff JB, Mongeau PA: Persuasive communication New York: The Guilford Press A Division of Guilford Publications, Inc; 2003.

22. Yang HM, Li XM, Bonita S, Fang XY, Zhao R, Dong B, Liu W, Liang S, Zhou $Y$, Hong Y: Condom use among female sex workers in China: role of gatekeepers. Sex Transm Dis 2005, 32:572-580.

23. Kerrigan D, Ellen JM, Moreno L, Rosario S, Katz J, Celentano DD, Sweat M: Environmental-structural factors significantly associated with consistent condom use among female sex workers in the Dominican Republic. AIDS 2003, 17:415-423.

24. Ford K, Wirawan DN, Reed BD, Muliawan P, Sutarga M: AIDS and STD knowledge, condom use and HIV/STD infection among female sex workers in Bali, Indonesia. AIDS Care 2000, 12:523-534.

25. Ao T, Sam N, Manongi R, Seage G, Kapiga S: Social and behavioural determinants of consistent condom use among hotel and bar workers in Northern Tanzania. Int J STD AIDS 2003, 14:688-696.

26. Wang B, Li XM, McGuire J, Kamali V, Fang XY, Stanton B: Understanding the dynamics of condom use among female sex workers in China. Sex Transm Dis 2009, 36:134-140.

27. Zhao R, Fan XYi, Li XM: Psychosocial factors influencing condom use behavior among female sex workers in China. Chinese Journal of Clinical Psychology 2006, 14:375-380.

28. Zhang DM, Tang ZH: Analysis of the influencing factors of condom use condition among high risk population of AIDS in China. Modern Preventive Medicine 2008, 35:3970-3971.

29. Fisher WA: Understanding and preventing adolescent pregnancy and sexually transmissible disease/AIDS. In Social influence processes and prevention. Volume 1. Edited by: Edwards J, Tinsdale RS, Heath C, Posavac EJ. New York: Plenum Press; 1990:71-101.

30. Fisher JD, Fisher WA: Theoretical approaches to individual-level change in HIV risk behavior.[http://digitalcommons.uconn.edu/chip_docs/4].
31. Bandura A: Perceived self-efficacy in the exercise of control over AIDS infection. In Primary Prevention of AIDS: Psychological Approaches. Edited by: Mays VM, Albee GW, Schneider SF. Newbury Park, California: Sage Publications; 1989:128-141.

32. Wang $H$, Wang $N$, Bi A, Wang G, Ding G, Jia M, Lu L, Smith K: Application of cumulative odds logistic model on risk factors analysis for sexually transmitted infections among female sex workers in Kaiyuan city, Yunnan Province, China. Sex Transm Infect 2009, 85:290-295.

33. Wang HB, Chen RY, Ding GW, Ma YL, Ma JG, Jiao JH, Wu ZL, Sharp GB, Wang N: Prevalence and predictors of HIV infection among female sex workers in Kaiyuan city, Yunnan Province, China. Int J Infect Dis 2009, 13:162-169.

34. Su JM, Liu YX, Wang XF, Li XY, Zhang YD, Wang QY: Correlation study of sex exchange and HIV-related risk behaviors among female drug users. Chin J Dis Control Prev 2008, 12:531-533.

35. Wu JL, Zhu JL, Xie LZ, Ruan YH: Studies of HIV-related risk factors among female sex workers. Chinese Journal of Drug Abuse Prevention and Treatment 2009, 15:34-35.

36. China CDC \& National Sentinel Surveillance Group: National HIV/AIDS sentinel surveillance report in 2003. Beijing: China CDC \& National Sentinel Surveillance Group; 2004.

37. Shandong Province CDC: Comprehensive report on HIV/AIDS in Shandong Province 2008. Jinan: Shandong Province CDC; 2009.

38. Wang Y, Li B, Zheng JH, Sengupta S, Emrick CB, Cohen MS, Henderson GE: Factors related to female sex workers' willingness to utilize VCT service: a qualitative study in Jinan city, northern China. AIDS Behav 2009, 13:866-872.

39. Shi ZL, Zhang QC, Ruan SM, Yang H, Zhu YW: Analysis on HIV/AIDS epidemic characteristics and transmission path in Jinan. Chin J Prev Med 2008, 2:131-132.

40. Douglas $\mathrm{DH}$ : Respondent-driven sampling: a new approach to the study of hidden populations. Social Problems 1997, 44:174-199.

41. Douglas DH: Respondent-driven sampling II: deriving valid population estimates from chain-referral samples of hidden populations. Social Problems 2002, 49:11-34.

42. Carey MP, Schroder KEE: Development and psychometric evaluation of the brief HIV knowledge questionnaire. AIDS EduC Prev 2002, 14:172-182.

43. Volpe EM, Nelson LE, Kraus RA, Morrison-Beedy D: Adaptation and refinement of the HIV knowledge questionnaire for use with adolescent girls. J Assoc Nurses AIDS Care 2007, 18:57-63.

44. Yang P, Wang QQ, Zhong MY: Evaluation of the effects of face-to-face education for the improvement of STI/AIDS related knowledge in female sex worker. Chin J AIDS STD 2006, 12:423-428.

45. Morisky DE, Stein JA, Chi C: Impact of a social influence intervention on condom use and sexually transmitted infections among establishmentbased female sex workers in the Philippines: a multilevel analysis. Health Psychol 2006, 25:595-603.

46. Bandura A: Perceived self-efficacy in the exercise of control over AIDS infection. Evaluation and Program Planning 1990, 13:9-17.

47. Hou JT, Wen ZL, Cheng ZJ: Structural equation model and application Beijing: Education Science Publishing House; 2004.

48. Hu LT, Bentler PM: Cutoff criteria for fit indexes in covariance structure analysis: conventional criteria versus new alternatives. Structural Equation Modeling 1999, 6:1-55.

49. Bandura A: Social cognitive theory and exercise of control over HIV infection. In Preventing AIDS: Theories and Methods of Behavioral Interventions. Edited by: DiClemente RJ, Peterson JL. New York: Plenum Press; 1994:89-116.

50. Hong Y, Fang XY, Li XM, Liu Y, Li MQ: Environmental support and HIV prevention behaviors among female sex workers in China. Sex Transm Dis 2008, 35:662-667.

51. Kerrigan D, Moreno L, Rosario S, Gomez B, Jerez H, Barrington C, Weiss E, Sweat M: Environmental-Structural interventions to reduce HIV/STI risk among female sex workers in the Dominican Republic. American Journal of Public Health 2006, 96:120-125.

52. Liao SS, Schensul J, Wolffers I: Sex-related health risks and implications for interventions with hospitality women in Hainan, China. AIDS Educ Prev 2003, 15:109-121.

53. Lau JT, Tsui HY, Siah PC, Zhang KL: A study on female sex workers in southern China (Shenzhen): HIV-related knowledge, condom use and STD history. AIDS Care 2002, 14:219-233. 
54. Huang Y, Henderson GE, Pan S, Cohen MS: HIV/AIDS risk among brothelbased female sex workers in China: assessing the terms, content, and knowledge of sex work. Sex Transm Dis 2004, 31:695-700.

55. Shuper PA, Joharchi N, Irving H, Rehm J: Alcohol as a correlate of unprotected sexual behavior among people living with HIV/AIDS: review and meta-analysis. AIDS Behav 2009, 13:1021-1036.

56. Wang B, Li XM, Stanton B, Zhang L, Fang XY: Alcohol use, unprotected sex, and sexually transmitted infections among female sex workers in China. Sex Transm Dis 2010, 37:629-636.

57. Szwarcwald CL, Bastos Fl, Gravato N, Lacerda R, Chequer PN, Castilho EA: The relationship of illicit drug use to HIV-infection among commercial sex workers in the city of Santos, São Paulo, Brazil. International Journal of Drug Policy 1998, 9:427-436.

58. Maisto SA, Carey MP, Carey KB, Gordon CM: The effects of alcohol and expectancies on risk perception and behavioral skills relevant to safer sex among heterosexual young adult women. I Stud Alcohol 2002, 63:476-485.

59. Needle R, Kroeger K, Belani H, Achrekar A, Parry CD, Dewing S: Sex, drugs, and HIV: rapid assessment of HIV risk behaviors among street-based drug using sex workers in Durban, South Africa. Social Science \& Medicine 2008, 67:1447-1455.

60. Ghimire L, Teijlingen E: Barriers to utilisation of sexual health services by female sex workers in Nepal. Global Journal of Health Science 2009, 1:12-22.

61. Zhu XY, Kang DM, Liao MZ, Liu XZ, Fu JH: Application of respondent drive sampling. Prev Med Trib 2007, 13:632-635.

62. Yeka W, Maibani-Michie G, Prybylski D, Colby D: Application of respondent driven sampling to collect baseline data on FSWs and MSM for HIV risk reduction interventions in two urban centres in Papua New Guinea. J Urban Health 2006, 83(suppl 6):60-72.

\section{Pre-publication history}

The pre-publication history for this paper can be accessed here: http://www.biomedcentral.com/1471-2458/11/113/prepub

doi:10.1186/1471-2458-11-113

Cite this article as: Zhang et al:: Predictors of consistent condom use based on the Information-Motivation-Behavioral Skills (IMB) model among female sex workers in Jinan, China. BMC Public Health 2011 11:113.

\section{Submit your next manuscript to BioMed Central and take full advantage of:}

- Convenient online submission

- Thorough peer review

- No space constraints or color figure charges

- Immediate publication on acceptance

- Inclusion in PubMed, CAS, Scopus and Google Scholar

- Research which is freely available for redistribution 